\title{
CLINICAL EXPERIENCE WITH THE CARBOMEDICS VALVE: EARLY RESULTS WITH A NEW BILEAFLET MECHANICAL PROSTHESIS
}

J. Francisco Nistal, MD Aquilino Hurlé, MD

José M. Revuelta, MD

Marco Gandarillas, $\mathrm{PhD}^{*}$
Between January 1989 and August 1992, 612 CarboMedics mechanical prostheses (CarboMedics, Inc., Austin, Tex.) (295 mitral, 308 aortic, and 9 tricuspid) were implanted in 504 patients: 189 patients had isolated mitral valve replacement, 209 had isolated aortic valve replacement, and 106 had multiple valve replacement. The total follow-up was 1182 patient-years. The hospital mortality rate was $\mathbf{7 . 4 \%}$ for mitral valve replacement, $5.3 \%$ for aortic valve replacement, and $13.2 \%$ for multiple valve replacement. Linearized rates for the different complications for mitral valve replacement, aortic valve replacement, and multiple valve replacement (in events per 100 patient-years) were, respectively, as follows: late mortality, $2.6 \pm$ $0.8,1.5 \pm 0.5$, and $3.9 \pm 1.3$; thromboembolim, $3.7 \pm 0.9,3.1 \pm 0.8$, and 3.9 \pm 1.3 ; valve thrombosis, $0.5 \pm 0.3$ for mitral valve replacement and $0.4 \pm$ 0.4 for multiple valve replacement; anticoagulant-related hemorrhage, 2.8 $\pm 0.8,1.9 \pm 0.6$, and $2.6 \pm 1.1$; nonstructural dysfunction, $1.6 \pm 0.6,0.8 \pm$ 0.4 , and $3.5 \pm 1.2$; and reoperation, $1.1 \pm 0.5,0.4 \pm 0.3$, and $3.1 \pm 1.1$. Actuarial estimates of freedom from the different complications for mitral valve replacement, aortic valve replacement, and multiple valve replacement (at 5 years of follow-up for mitral valve replacement and aortic valve replacement and 4.5 years for multiple valve replacement) were, respectively, as follows: overall death, $83 \% \pm 4 \%, 89 \% \pm 2 \%$, and $76 \% \pm 4 \%$; thromboembolism or valve thrombosis, $88 \% \pm 3 \%, 91 \% \pm 2 \%$, and $86 \% \pm$ 5\%; anticoagulant-related hemorrhage, $89 \% \pm 3 \%, 95 \% \pm 2 \%$, and $90 \% \pm$ $5 \%$; nonstructural dysfunction, $97 \% \pm 1 \%, 98 \% \pm 1 \%$, and $91 \% \pm 3 \%$; and reoperation, $96 \% \pm 2 \%, 99 \% \pm 1 \%$, and $87 \% \pm 5 \%$. There were no instances of prosthetic structural dysfunction. The performance of the CarboMedics valve is satisfactory at 5 years of follow-up but thromboembolic and hemorrhagic phenomena are still serious complications of mechanical prostheses. (J Thorac Cardiovase Surg 1996;112:59-68)
Bis ileaflet mechanical heart valves have demonstrated, during the past 16 years, their superiority over previous designs in terms of lower transvalvular gradients, a more physiologic flow pattern distribution, and, possibly, a lower thrombogenic potential. ${ }^{1}$ A valve design based on two occluders, as opposed

From the Department of Cardiovascular Surgery, Hospital Marqués de Valdecilla, University of Cantabria, Santander, Spain.

Received for publication April 10, 1995; accepted for publication August 30, 1995.

Address for reprints: J. F. Nistal, MD, Servicio de Cirugía Cardiovascular, Hospital Universitario Marqués de Valdecilla, Avda. de Valdecilla s/n, 39008 Santander, Spain.

${ }^{*}$ Consultant statistician.

Copyright (C) 1996 by Mosby-Year Book, Inc.

$0022-5223 / 96 \$ 5.00+0 \quad 12 / 1 / 68911$ to a single occluder, should provide, in theory at least, greater functional safety although it entails the use of a double hinge mechanism. Clinical experience with the St. Jude Medical valve (St. Jude Medical Inc., St. Paul, Minn.) has shown a low rate of structural failure and thrombotic complications. ${ }^{2-5}$

The CarboMedics bileaflet valve, manufactured by a company with a vast experience in the production of pyrolytic carbon (CarboMedics, Inc., Austin, Tex.), was approved for clinical use by the Spanish authorities in 1987. Its main advantage over other bileaflet models was the possibility of rotation once implanted, achieved by means of a new sewing ring design.

The aim of the current study was to analyze the short-term performance of the CarboMedics valve. 
Table I. Associated operations

\begin{tabular}{lccc}
\hline \multicolumn{1}{c}{ Procedures } & MVR & AVR & MultiVR \\
\hline Mitral valve repair & 0 & 6 & 0 \\
LA thrombectomy/ligation & 22 & 2 & 7 \\
$\quad$ of appendage & & & \\
Tricuspid valve repair & 30 & 1 & 10 \\
Aortic operation & 0 & 13 & 3 \\
Coronary artery operation & 7 & 7 & 1 \\
Other & 2 & 1 & 4 \\
\hline
\end{tabular}

$L A$, Left atrial.

Table II. Demographics

\begin{tabular}{lrrrrrr} 
& \multicolumn{3}{c}{ Age } & & \multicolumn{2}{c}{ Gender } \\
\cline { 2 - 4 } \cline { 6 - 7 } Group & Mean & \multicolumn{1}{c}{ SD } & Range & \multicolumn{1}{c}{ Male } & \multicolumn{1}{c}{ Female } \\
\hline MVR & 54.5 & 10.5 & $20-75$ & & $65(34 \%)$ & $124(66 \%)$ \\
AVR & 54.1 & 11.1 & $15-74$ & & $155(74 \%)$ & $54(26 \%)$ \\
MultiVR & 54.7 & 9.5 & $29-75$ & & $47(44 \%)$ & $59(56 \%)$ \\
\hline
\end{tabular}

$S D$, Standard deviation.

For this purpose, we conducted the following singlecenter, observational, retrospective, and patientoriented survey.

\section{Patients and methods}

Between January 1989 and August 1992, 504 consecutive patients received a total of 612 CarboMedics mechanical valves in our unit. Mitral valve replacement (MVR) was done in 189 patients, aortic valve replacement (AVR) in 209 patients, and multiple valve replacement (MultiVR) in 106 patients (mitral and aortic valve replacement in 97 patients, mitral and tricuspid valve replacement in 7 patients, and trivalvular replacement in 2 patients). The total number of valves implanted was 295 in the mitral position, 308 in the aortic position, and 9 in the tricuspid position. All patients were operated on with the use of extracorporeal circulation and moderate hypothermia. Myocardial protection was achieved with the antegrade infusion of either hematic or crystalloid cardioplegic solution and topical cooling with cold saline solution. Concomitant procedures are shown in Table I.

Anticoagulation with oral acenocoumarol was started in all cases as soon as the patient was capable of oral intake. After discharge from the hospital, the patients were referred to their local anticoagulation clinics with the recommendation to maintain an international normalized ratio (INR) of 2.5 to 3 .

We reviewed the data in the manner of a patientoriented retrospective study. Data were collected during the regular visits of the patients to the outpatient clinic, from the medical records, or by telephone interview. The closing interval was 6 weeks and the follow-up was $97 \%$ complete, with information lacking from 15 patients. All patients included in the study who survived and did not undergo reoperation had a minimum follow-up of 12 months.
Table III. Cause of valvular disease

\begin{tabular}{lccc}
\hline \multicolumn{1}{c}{ Cause } & MVR & AVR & MultiVR \\
\hline Rheumatic & $11(59 \%)$ & $51(24 \%)$ & $51(48 \%)$ \\
Degenerative & - & $99(47 \%)$ & - \\
Prosthetic dysfunction & $59(31 \%)$ & $47(22 \%)$ & $46(43 \%)$ \\
Infective & $5(2 \%)$ & $10(5 \%)$ & $4(4 \%)$ \\
Ischemic & $4(2 \%)$ & - & $1(1 \%)$ \\
Other & $10(5 \%)$ & $2(1 \%)$ & $4(4 \%)$ \\
\hline
\end{tabular}

The guidelines of the liaison committee of the AATSSTS-EACTS* for reporting morbidity and mortality after cardiac valvular operations were followed ${ }^{6}$

Complications that appeared with a nonbiased time course were expressed by means of linearized rates. Actuarial analysis was done by the Kaplan-Meier method. ${ }^{7}$ Comparison between actuarial estimates was done by use of normal distribution. Continuous variables were compared by a two-tailed Students $t$ test. Categorical data were compared by a $2 \times 2$ contingency table or a $\chi^{2}$ test, corrected if appropriate by Yates' formula or Fisher's exact test. Assessment for preoperative risk factors of the main postoperative complications was done, when the number of events was sufficient, by bivariate analysis (with Mann-Whitney or $\chi^{2}$ tests, corrected if necessary) and with multivariate analysis by means of stepwise logistic regression analysis or Coxs proportional hazards regression model. Values of relative risk (RR) or odds ratios are given herein, together with $95 \%$ confidence limits $(\mathrm{CL})$. Significance levels lower than 0.05 were considered meaningful.

\section{Results}

The mean age of the patients was 54 years for MVR, AVR, and MultiVR, with a range of 15 to 75 years for the complete group (Table II). The patient was female in $66 \%$ of MVR, $26 \%$ of AVR, and $56 \%$ of MultiVR cases (Table II). The cause of the valvular disease (Table III) was predominantly rheumatic among patients with mitral and multivalvular disease and degenerative in the aortic group. Replacement of a failing prosthesis (bioprostheses in most cases) constituted the indication for operation in $31 \%$ of MVR, $22 \%$ of AVR, and $43 \%$ of MultiVR recipients.

The most common implantation valve sizes were, in order of frequency, 29, 31, and $27 \mathrm{~mm}$ for MVR; 21, 23, and $25 \mathrm{~mm}$ for AVR, and $31 \mathrm{~mm}$ for tricuspid valve replacement.

The total follow-up was 1182 patient-years: 431 patient-years in the MVR group, 522 patient-years in the AVR group, and 228 patient-years in the

\footnotetext{
*The American Association for Thoracic Surgery, Society of Thoracic Surgeons, and European Association of Cardiothoracic Surgery.
} 
Table IV. Hospital mortality

\begin{tabular}{lccc}
\multicolumn{1}{c}{ Causes } & MVR & AVR & MultiVR \\
\hline Low cardiac output & 7 & 4 & 4 \\
Hemorrhage & 4 & 3 & 6 \\
AMI & 1 & 1 & 1 \\
Stroke & 0 & 1 & 0 \\
Tamponade & 1 & 0 & 0 \\
Sepsis & 0 & 1 & 0 \\
Endocarditis & 0 & 0 & 1 \\
Multiorgan failure & 1 & 0 & 1 \\
Unknown & 0 & 1 & 1
\end{tabular}

AMI, Acute myocardial infarction.

MultiVR group, with a mean follow-up of 2.5 years per patient for each of the cohorts.

Mortality. The hospital mortality rate (within 30 days of operation or before hospital discharge) was 7.7\% (39 patients) for the complete group: $7.4 \%$ (14 patients) for MVR, 5.3\% (11 patients) for AVR, and $13.2 \%$ (14 patients) for MultiVR. Hospital deaths were most commonly caused by perioperative hemorrhage or low cardiac output syndrome (Table IV). Three deaths were caused by embolic phenomena (1 stroke, 2 embolic myocardial infarctions). Statistically significant preoperative predictors of hospital mortality, for the whole population of patients, included atrial fibrillation $(p=0.012$, RR $2.9,95 \%$ CL 1.3 to 6.7 ), cause of disease ( $p=$ 0.012 , RR 1.4, 95\% CL 1.1 to 1.7), New York Heart Association functional class ( $p=0.03, \mathrm{RR} 1.7,95 \%$ CL 1.1 to 2.7), and associated surgical procedures ( $p=0.04$, RR 1.3, 95\% CL 1.0 to 1.6). For patients with isolated mitral valve disease the only significant predictor in the multivariable analysis was the functional class $(p=0.005$, RR $4.3,95 \%$ CL 1.5 to 11.8$)$, and for the group with isolated aortic valve disease the only significant predictor was atrial fibrillation ( $p=0.02$, RR $5.2,95 \%$ CL 1.3 to 19.8). Hospital mortality because of low cardiac output was significantly associated, for the whole cohort of patients, with a higher functional class ( $p=0.006, \mathrm{RR} 2.9$, 95\% CL 1.4 to 6.3 ) and associated surgical maneuvers ( $p<0.05$, RR $1.4,95 \%$ CL 1.0 to 1.7$)$.

Twenty-eight patients died late after operation: 11 in the MVR group, 8 in the AVR group, and 9 in the MultiVR group. Late deaths were most often of valvular or cardiac origin (Table V). Fatal embolic complications appeared in 4 patients ( 3 strokes and 1 peripheral embolism). Linearized rates for late death were $2.6 \pm 0.8$ deaths $/ 100 \mathrm{pt}$-yr for MVR, 1.5 \pm 0.5 for AVR, and $3.9 \pm 1.3$ for MultiVR. Actuarial survival estimates (including hospital mortal-
Table V. Late mortality

\begin{tabular}{llcc}
\multicolumn{1}{c}{ Causes } & MVR & AVR & MultiVR \\
\hline Congestive HF & 4 & 1 & 4 \\
Stroke & $2^{*}$ & 2 & 0 \\
Embolism & 1 & 0 & 0 \\
AMI & 1 & 0 & 0 \\
Respiratory failure & 1 & 0 & 0 \\
Endocarditis & 0 & 0 & 1 \\
Sudden death & 2 & 3 & 3 \\
Other & 0 & 2 & 1 \\
\hline
\end{tabular}

$H F$, Heart failure; $A M I$, acute myocardial infarction. *One hemorrhagic and one thromboembolic.

ity) were $83 \% \pm 4 \%$ for MVR and $89 \% \pm 2 \%$ for AVR at 5 years and $76 \% \pm 4 \%$ for MultiVR at 4.5 years (Fig. 1). A higher preoperative functional class was a significant predictor for late mortality, considering the whole population of patients $(p=0.03$, odds ratio $1.8,95 \%$ CL 1.0 to 3.0 ).

There were a total of 21 valve-related deaths in the complete group: 5 in the MVR group, 9 in the AVR group, and 7 in the MultiVR group. The linearized rates for valve-related death were $1.2 \pm$ 0.5 events $/ 100$ pt-yr for MVR, $1.7 \pm 0.6$ for AVR, and $3.1 \pm 1.2$ for MultiVR. Actuarial estimates of freedom from valve-related mortality were $96 \% \pm$ $2 \%$ for MVR and $94 \% \pm 2 \%$ for AVR at 5 years of follow-up and $91 \% \pm 3 \%$ for MultiVR at 4.5 years of follow-up (Fig. 2).

Thromboembolism and valve thrombosis. Overall, there were 41 thromboembolic events in 38 patients (Table VI). The linearized embolic rates were $3.7 \pm$ 0.9 events/100 pt-yr for MVR, $3.1 \pm 0.8$ for AVR, and $3.9 \pm 1.3$ for MultiVR. The rates for death caused by thromboembolic events were $0.5 \pm 0.3$ deaths/100 pt-yr for MVR, $0.8 \pm 0.4$ for AVR, and $0.4 \pm 0.4$ for MultiVR. Rates for permanent impairment of embolic origin were $1.2 \pm 0.5$ events/100 pt-yr for MVR, $1.0 \pm 0.4$ for AVR, and $1.7 \pm 0.9$ for MultiVR. Age was a significant preoperative predictor of thromboembolism after operation for the total cohort of patients $\left(\chi^{2}=5.12, p=0.02\right)$.

Three episodes of valve thrombosis were recorded. The three patients underwent reoperation and the prostheses were replaced (by two bioprostheses and one similar mechanical valve) with one resulting death. The linearized rates for thrombosis were $0.5 \pm 0.3$ events $/ 100 \mathrm{pt}$-yr for MVR and $0.4 \pm$ 0.4 for MultiVR (Table VI).

Actuarial probabilities of freedom from thromboembolism or valve thrombosis (Fig. 3) were $88 \% \pm$ $3 \%$ for MVR and $91 \% \pm 2 \%$ for AVR at 5 years of 


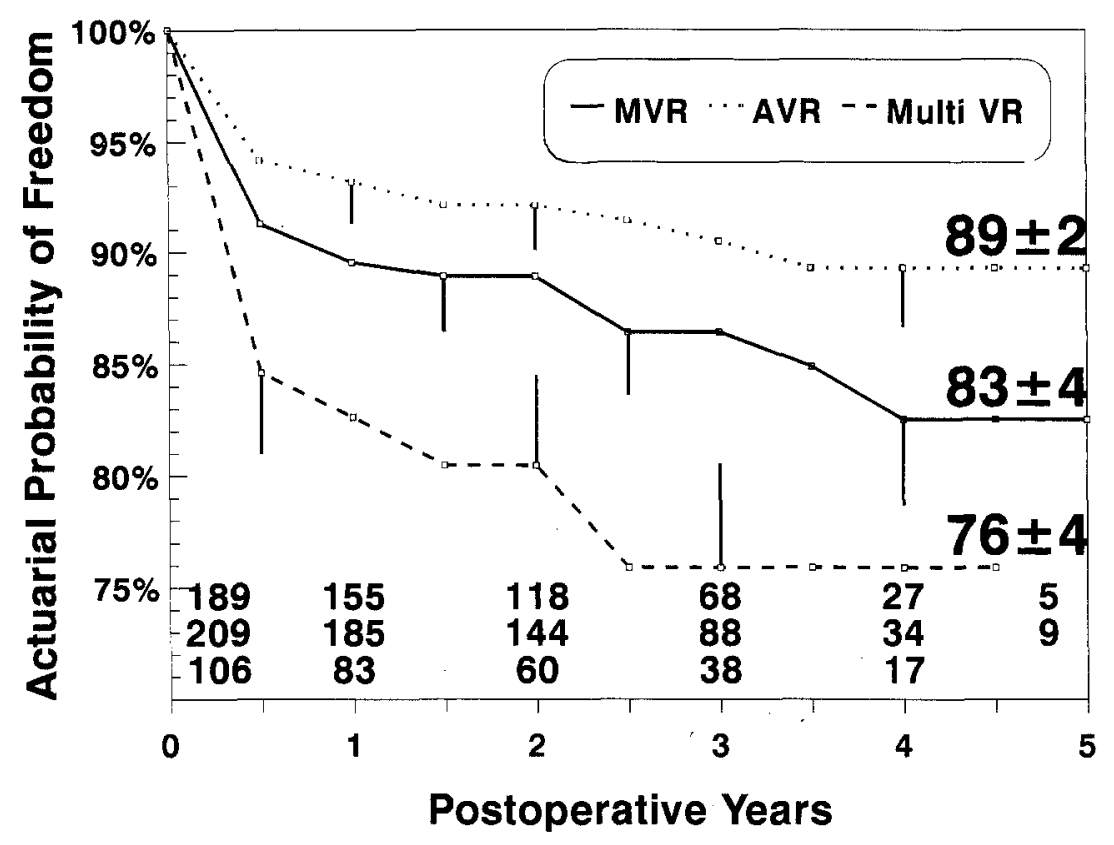

Fig. 1. Overall mortality (including hospital and late mortality): actuarial analysis.

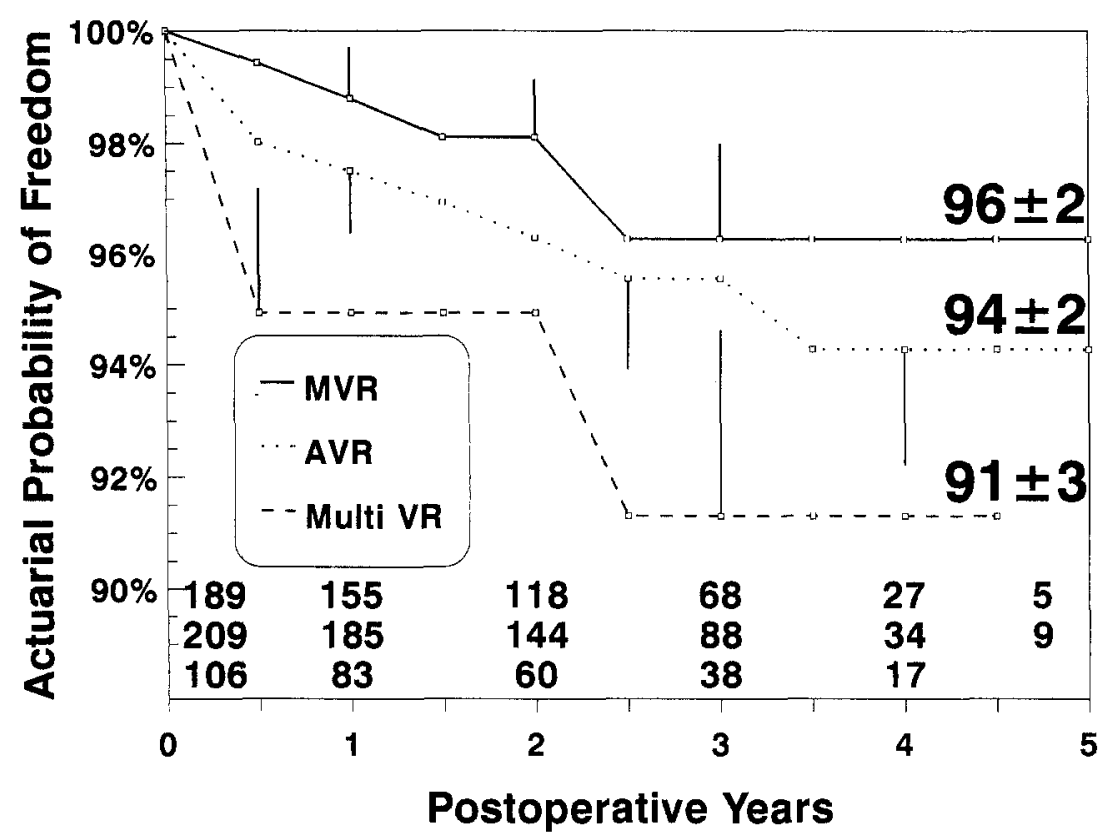

Fig. 2. Valve-related mortality: actuarial analysis.

follow-up and $86 \% \pm 5 \%$ for MultiVR at 4.5 years of follow-up.

Anticoagulant-related hemorrhage. There were 28 significant hemorrhagic events in 25 patients that necessitated admission of the patient to the hospital, with or without transfusion. The linearized rates for this complication were $2.8 \pm 0.8 / 100$ pt-yr for MVR, $1.9 \pm 0.6$ for AVR, and $2.6 \pm 1.1$ for MultiVR (Table VI). One patient with mitral valve disease died as a result of an intracerebral hemorrhage. The actuarial estimates of freedom from significant hemorrhagic complications (Fig. 4) were $89 \% \pm 3 \%$ and 


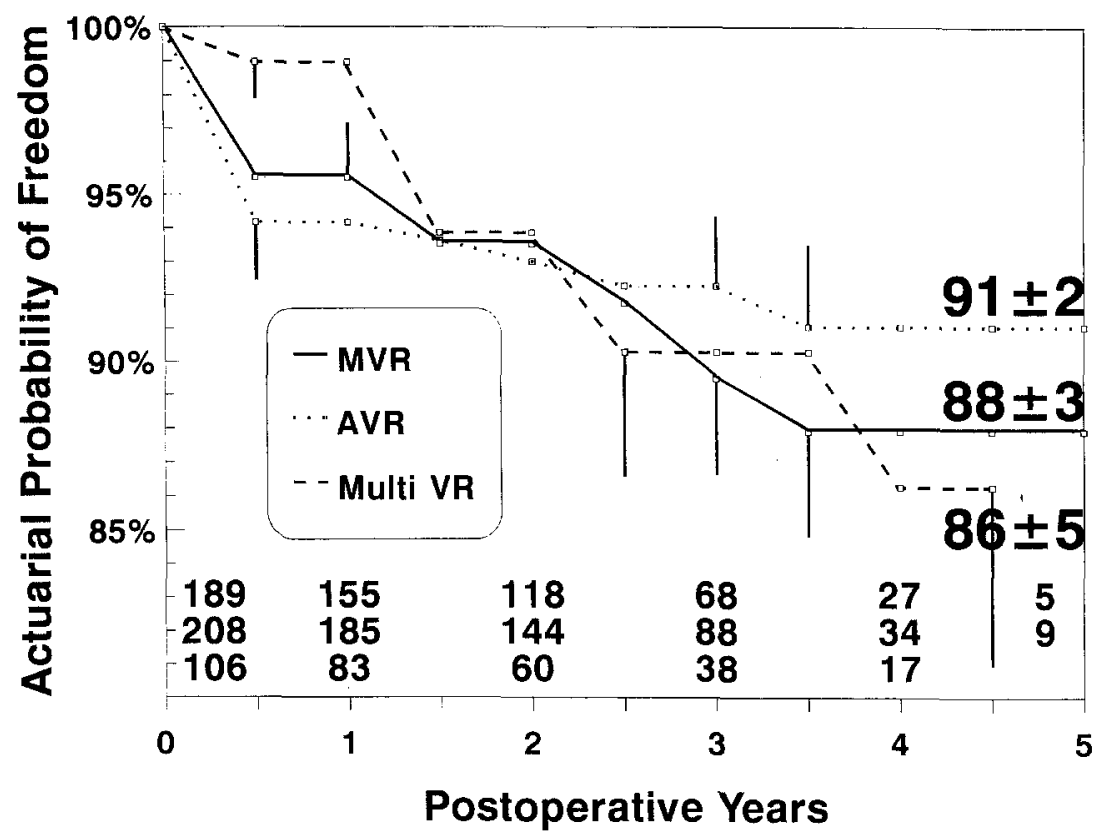

Fig. 3. Thromboembolism and valve thrombosis: actuarial analysis.

Table VI. Complications

\begin{tabular}{|c|c|c|c|c|c|c|c|c|c|}
\hline & \multicolumn{3}{|c|}{$M V R$} & \multicolumn{3}{|c|}{$A V R$} & \multicolumn{3}{|c|}{ MultiVR } \\
\hline & Patients & Events & $L R$ & Patients & Events & $L R$ & Patients & Events & $L R$ \\
\hline Thromboembolism & 14 & 16 & $3.7 \pm 0.9$ & 16 & 16 & $3.1 \pm 0.8$ & 8 & 9 & $3.9 \pm 1.3$ \\
\hline Valve thrombosis & 2 & 2 & $0.5 \pm 0.3$ & - & - & $-\quad-$ & $1^{*}$ & 1 & $0.4 \pm 0.4$ \\
\hline Hemorrhage & 12 & 12 & $2.8 \pm 0.8$ & 8 & 10 & $1.9 \pm 0.6$ & 5 & 6 & $2.6 \pm 1.1$ \\
\hline Endocarditis & - & - & -- & - & - & $-\ldots$ & 2 & 2 & $0.9 \pm 0.6$ \\
\hline Nonstructural dysfunction & 6 & 7 & $1.6 \pm 0.6$ & 3 & 4 & $0.8 \pm 0.4$ & 7 & 8 & $3.5 \pm 1.2$ \\
\hline Reoperation & 5 & 5 & $1.1 \pm 0.5$ & 2 & 2 & $0.4 \pm 0.3$ & 7 & 7 & $3.1 \pm 1.1$ \\
\hline
\end{tabular}

$L R$, Linearized rate (in events per $100 \mathrm{p}-\mathrm{y}$ ) plus or minus standard error.

${ }^{*}$ Thrombosis on tricuspid valve.

$95 \% \pm 2 \%$ for MVR and AVR, respectively, at 5 years and $90 \% \pm 5 \%$ for MultiVR at 4.5 years of follow-up.

Nonstructural dysfunction. Nineteen instances of nonstructural dysfunction (hemolysis or periprosthetic leak, or both) were evidenced in 16 patients (Table VI). Overall, there were five cases of hemolysis, which includes those of two patients who showed clinical hemolysis without demonstrated periprosthetic leak.

Linearized rates for dysfunction were $1.6 \pm 0.6$ events/100 pt-yr for MVR, $0.8 \pm 0.4$ for AVR, and $3.5 \pm 1.2$ for MultiVR. Actuarial analysis revealed probabilities of freedom from this complication of $97 \% \pm 1 \%$ for MVR and $98 \% \pm 1 \%$ for AVR at 5 years and $91 \% \pm 3 \%$ for MultiVR at 4.5 years of follow-up (Fig. 5).
Prosthetic endocarditis. Two cases of endocarditis were detected in two patients from the MultiVR group (Table VI). One of them underwent reoperation and died 2 months later of recurrent valve infection. The other patient died of septicemia before operation could be done.

Reoperation. A total of 14 patients required reoperation: 5 in the MVR group, 2 in the AVR group, and 7 in the MultiVR group (Table VI). The reasons for reoperation were periprosthetic leak in 8 patients ( 1 in MVR group, 2 in AVR group, and 5 in MultiVR group), valve thrombosis in 3 ( 2 in MVR group and 1 in MultiVR group), and prosthetic endocarditis in 1 patient with combined mitral and aortic valvular disease. Two other patients with mitral disease, with normally functioning prostheses, underwent reoperation because of severe tricuspid 


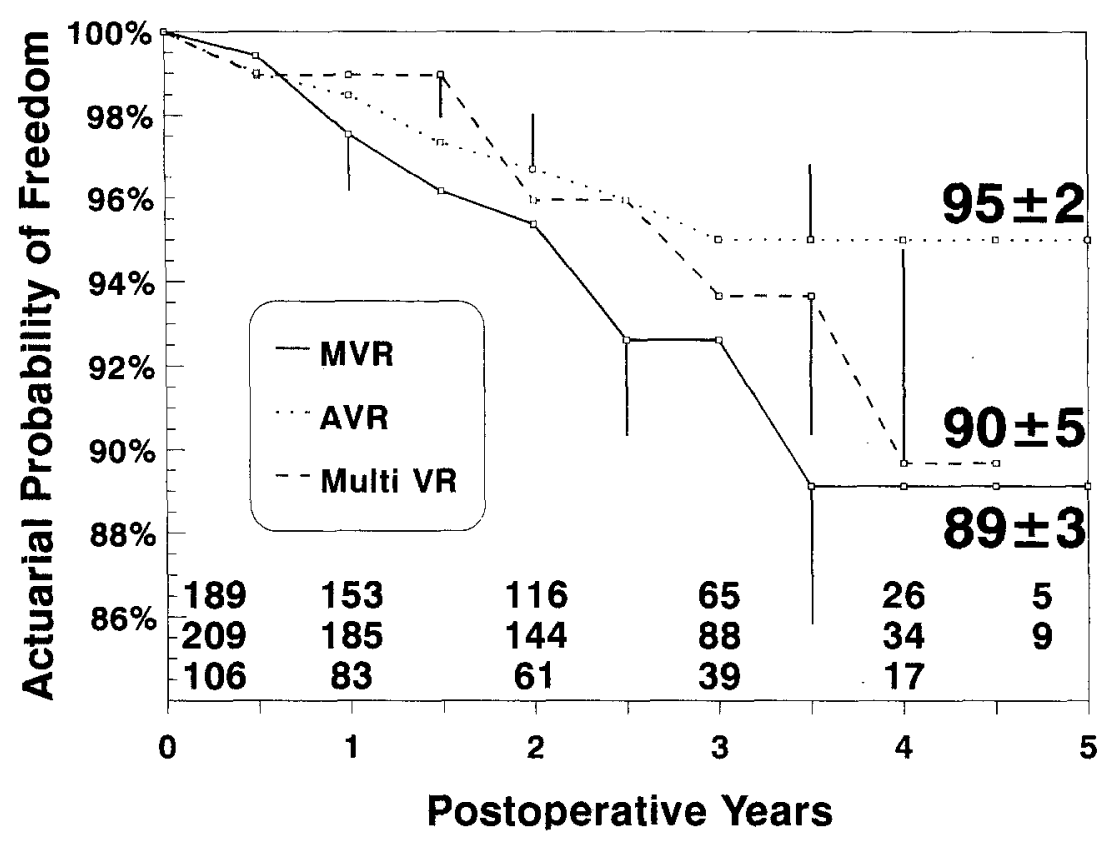

Fig. 4. Anticoagulant-related hemorrhage: actuarial analysis.

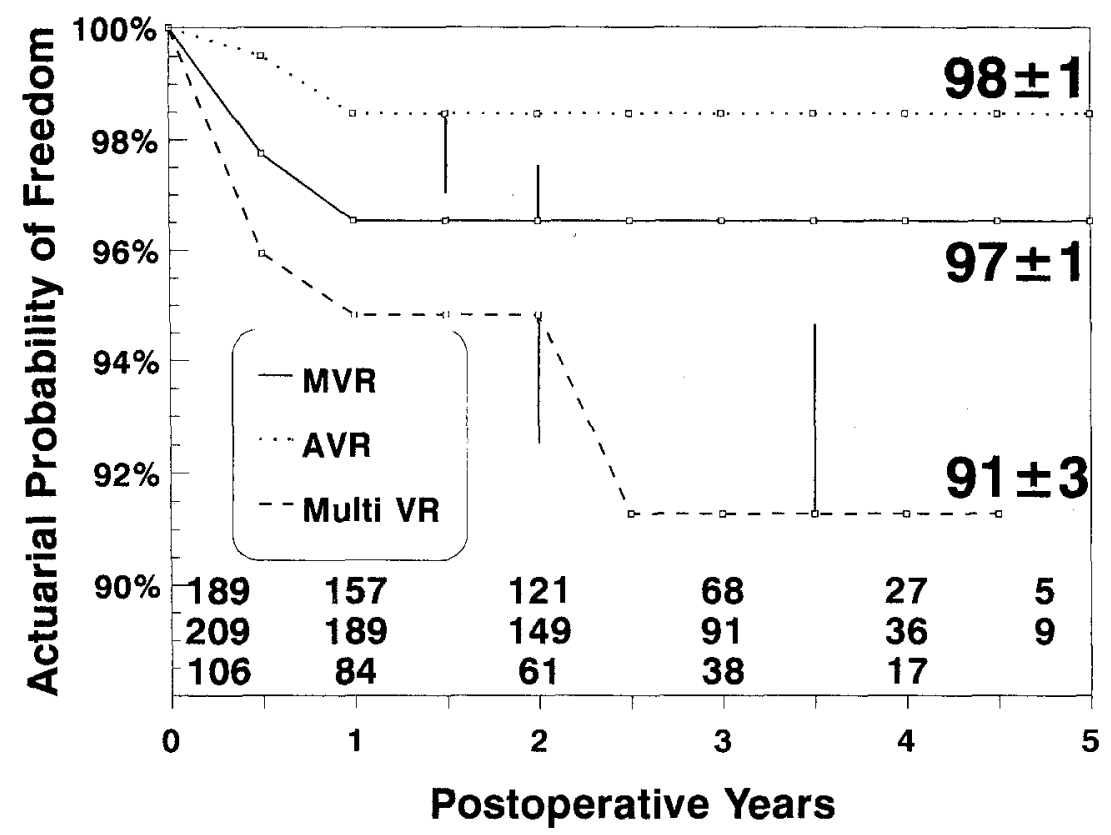

Fig. 5. Nonstructural dysfunction: actuarial analysis.

insufficiency and for a heart transplantation, respectively. There were three cases of reoperation-related death: one MVR recipient with a thrombosed prosthesis, one AVR recipient who underwent reoperation because of a periprosthetic leak, and one MultiVR recipient with prosthetic endocarditis.
Linearized reoperation rates were $1.1 \pm 0.5$ events/100 pt-yr for MVR, $0.4 \pm 0.3$ for AVR, and $3.1 \pm 1.1$ for MultiVR. The actuarial probabilities of freedom from reoperation were $96 \% \pm 2 \%$ and $99 \% \pm 1 \%$ for MVR and AVR at 5 years and $87 \%$ $\pm 5 \%$ for MultiVR at 4.5 years of follow-up (Fig. 6). 


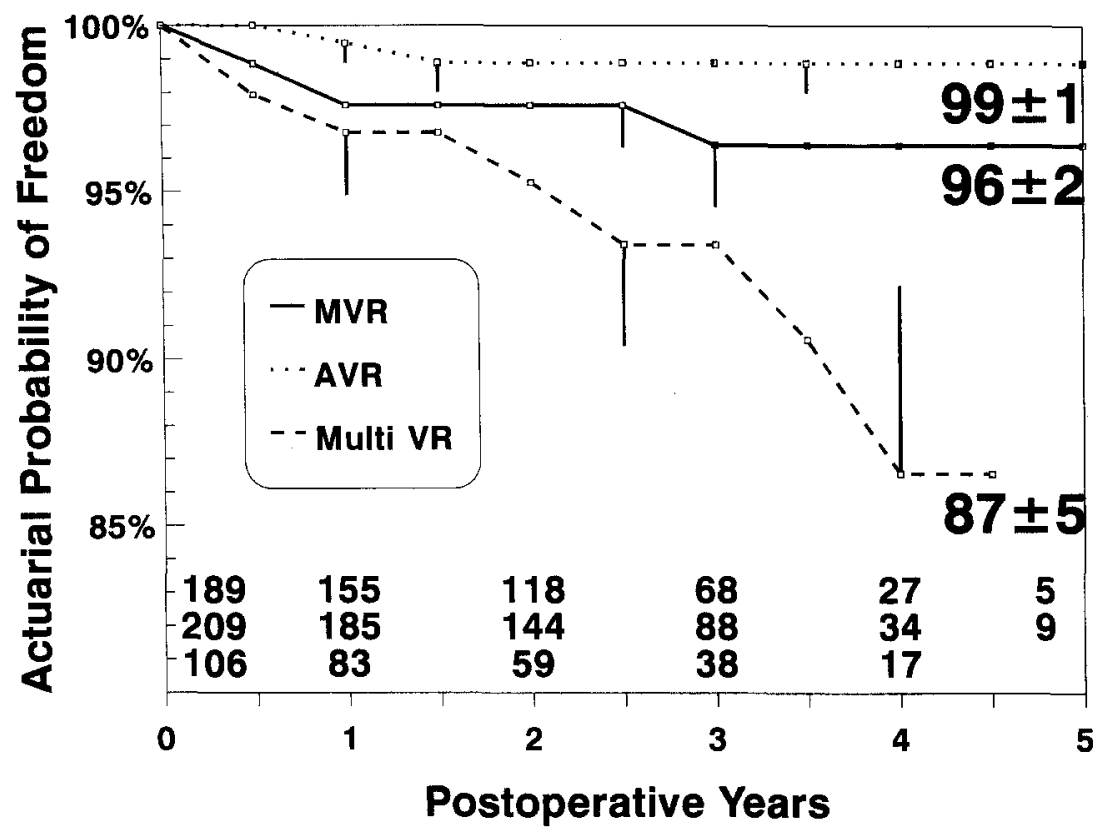

Fig. 6. Reoperation: actuarial analysis.

Structural dysfunction. No cases of reoperation or death were recorded as the result of structural dysfunction. There was no clinical evidence of intrinsic valve failure in any patient in this study.

Functional status and valve-related morbidity and mortality. More than $80 \%$ of the patients in the MVR and MultiVR groups and nearly $50 \%$ in the AVR group had New York Heart Association class III or IV disease before operation. Postoperative functional class was I or II in at least $90 \%$ of the patients in each of the cohorts. However, small groups of patients with class III or IV symptoms persist, particularly in the MVR and MultiVR groups (Table VII).

Actuarial estimates of freedom from any valverelated morbidity or mortality were $68 \% \pm 4 \%$ and $79 \% \pm 3 \%$ for MVR and AVR at 5 years and $62 \%$ $\pm 6 \%$ at 4.5 years of follow-up for MultiVR (Fig. 7). A significant difference $(p<0.05)$ between the AVR and the MultiVR curves is noted after the second year of follow-up.

\section{Discussion}

Bileaflet design of mechanical heart valve prostheses dates back at least to 1964 and 1969, when the Gott-Daggett and the Kalke-Lillehei devices were described. ${ }^{8,9}$ Both of these prosthetic designs failed as a result of thrombotic phenomena, even though Dr. Gotts valve had, as an innovative technical
Table VII. Functional class before and after operation

\begin{tabular}{|c|c|c|c|c|c|c|}
\hline & \multicolumn{2}{|c|}{$M V R$} & \multicolumn{2}{|c|}{$A V R$} & \multicolumn{2}{|c|}{ MultiVR } \\
\hline & Preop. & Postop. & Preop. & Postop. & Preop. & Postop. \\
\hline \multicolumn{7}{|c|}{ NYHA class $(\%)$} \\
\hline I & 1 & 64 & 14 & 77 & 7 & 61 \\
\hline II & 14 & 26 & 38 & 19 & 12 & 29 \\
\hline III & 65 & 10 & 34 & 4 & 59 & 8 \\
\hline IV & 20 & 一 & 14 & - & 22 & 2 \\
\hline
\end{tabular}

NYHLA, New York Heart Association.

characteristic, a treatment of the leaflets with pyrolytic carbon (graphite) that would supposedly prevent these complications. The experimental and clinical success of this design had to wait until the mid-1970s, when the technology of pyrolytic carbon was well established. In 1979, Emery, Mettler, and Nicoloff ${ }^{10}$ reported the first series of clinical implants of the St. Jude Medical valve, with excellent early results in terms of thromboembolism and hemodynamics. Several other groups have delineated the in vitro and in vivo hemodynamic characteristics of this prosthesis and have reported its clinical follow-up, which currently goes beyond the 15-year mark. ${ }^{2-5,11-15}$

In 1987 the CarboMedics heart valve prosthesis was approved for clinical use in Spain, and late in 1993 the Food and Drug Administration authorized 


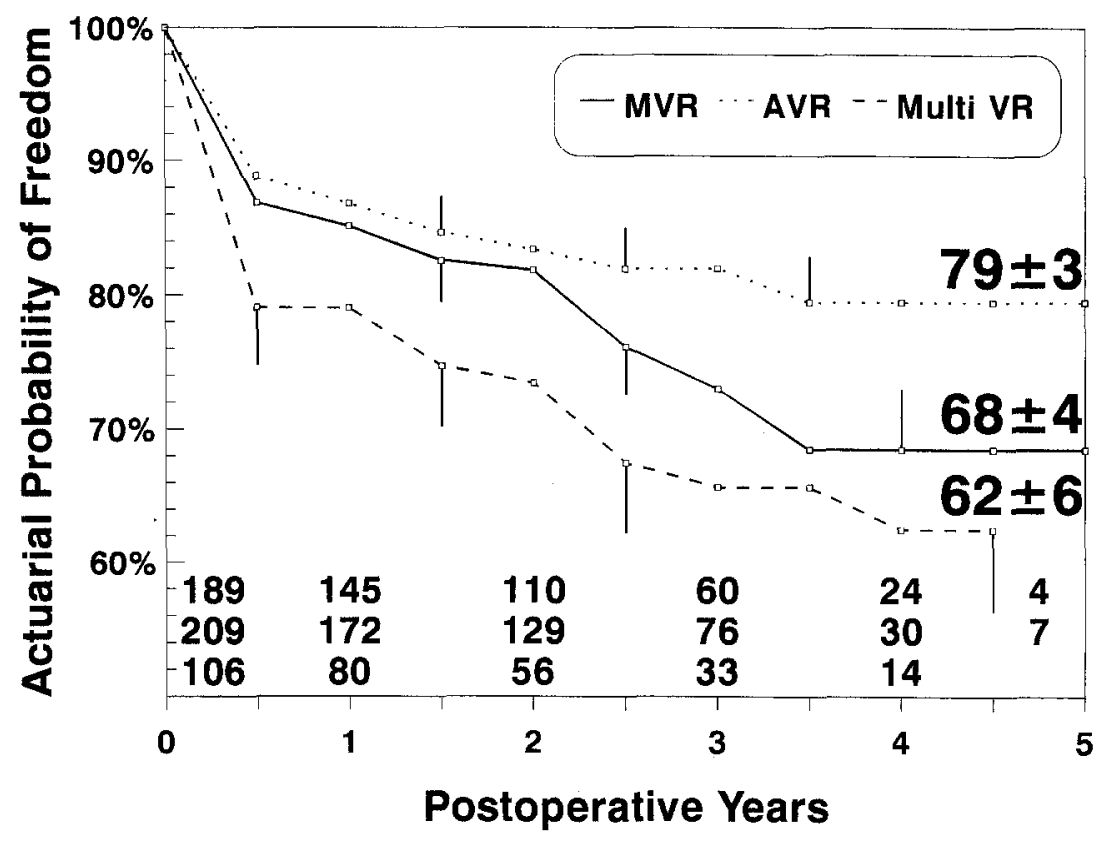

Fig. 7. All valve-related morbidity and mortality: actuarial analysis. There is statistically significant difference between AVR and MultiVR after second year of follow-up.

the use of this implant in the United States. The main advantage of this device over previous bileaflet designs was the possibility of rotating the cage against the sewing ring after the valve was in position. This feature would, theoretically, help avoid interference of valve remnants or other structures with the valve mechanism and would be of particular interest when this device was implanted on nonresected atrioventricular valves. ${ }^{16}$ On the other hand, its in vitro and in vivo hydrodynamic characteristics have been shown to be comparable to those of the St. Jude Medical prosthesis. ${ }^{15,17,18}$

The current study is a single-institution study, which is, in our opinion, the best way to analyze the performance of a prosthetic valve without the biases intrinsic to cooperative multi-institutional studies that include heterogeneous populations. ${ }^{19,}{ }^{20}$ Before we begin the comparative analysis of our data, some specific characteristics of our patient population should be considered: (1) we studied a group of middle-aged patients with moderate symptoms with a significant proportion of rheumatic pathologic conditions (Table III); (2) dysfunction of a previous prosthesis constituted the indication for operation in a large proportion of patients in each of the MVR, AVR, and MultiVR groups (Table III); (3) ischemic heart disease was the main cause of the valve disease in only a few patients (Table III) and associated revascularization procedures were not common (Table I); (4) an aggressive attitude against tricuspid pathologic conditions was maintained, with a significant number of reparative procedures (Table I); and (5) oral anticoagulation therapy was prescribed for all patients, but the INR target value was in the lower range of current recommendations. ${ }^{21}$ Early anticoagulation with intravenous sodium heparin was not used.

Our patients had a relatively young mean age, which was comparable to that in several other surveys in the literature, ${ }^{3,5,22,23}$ and a prevalence of ischemic heart disease and coronary bypass procedures similar to that in some reports. ${ }^{5}, 22$ Our hospital mortality rates are somewhat higher than those reported by other investigators and are probably influenced by a considerable proportion of re-replacement procedures and the greater prevalence of tricuspid valve disease in our cohort. Our overall long-term survival, however, is similar to the survivals that have been reported in patient populations with comparable demographic and clinical characteristics and better than the rates from other American reviews dealing with older and sicker patients. $^{4,24}$ The actuarial estimates of freedom from valve-related mortality at 5 years are, in our study, similar to those in most recent investigations on last-generation, tilting disk or bileaflet mechanical 
prostheses..$^{3-5,22-24}$ In our experience, the overall survival rates at the 5-year mark are significantly worse than valve-related survival probabilities. This difference is even greater in studies done in populations with a worse preoperative profile in terms of predictors for long-term prognosis. ${ }^{4,24}$ Hence the ultimate fate of the patients seems to be determined more by cardiac nonvalvular or noncardiac complications than by valve-related events, which is a generalized finding in recent studies. ${ }^{3-5,19}$

Our anticoagulation policy shows some differences compared with those of other series and is based on the current evidence that a less intense anticoagulation regimen (1) should not necessarily be penalized by an increased number of thrombotic complications and (2) is linearly accompanied by a decreased prevalence of hemorrhagic phenome$\mathrm{na}^{25,26}$ Also, several other long-term follow-up studies showed a progressive reduction in the target INR value with time with no increase in thromboembolic rates. ${ }^{3,4}$ Our patients did not receive heparin early after operation and the INR target values were 2.5 to 3 , which is lower than the value that is customary in most units in the United States but which is in accordance with the current recommendations of the American College of Chest Physicians. $^{21}$ This different policy might explain the slightly higher thromboembolic rates in our study compared with the rates in the studies of Kratz, ${ }^{3}$ Khan, ${ }^{4}$ Copeland, ${ }^{23}$ Aoyagi, ${ }^{5}$ and their co-workers on bileaflet prostheses, although the differences disappear when the comparison is made with earlier tilting disk prostheses. ${ }^{24}$ One should also consider the profile of our patient population, with its relatively low mean age, and the fact that we are dealing with last-generation bileaflet valves. These characteristics allow a decrease in the INR target values while still being in the safe range, as has been recently shown. ${ }^{27,28}$ Also, the hemorrhagic complications associated with anticoagulant treatment are usually more severe, in terms of mortality or permanent impairment, than the thromboembolic counterparts. ${ }^{27}$

The morbid consequences of thromboembolic phenomena, namely death and permanent impairment, are equally frequent in our and other authors' experience, ${ }^{3,23}$ which suggests that the increase in the overall number of embolic phenomena observed with our antithrombotic policy occurs mainly at the expense of the number of minor episodes.

On the other hand, anticoagulant-related hemorrhagic events were few in our experience. One of our patients died, but we had no instance of permanent impairment caused by hemorrhagic complications, whereas Kratz and associates ${ }^{3}$ reported linearized rates for death or permanent deficit of this origin of $0.6 \pm 0.2$ events $/ 100 \mathrm{pt}-\mathrm{yr}$ for AVR and $0.3 \pm 0.2$ for MVR, and Copeland ${ }^{23}$ found an overall death rate of this origin of 0.6 events/ $100 \mathrm{pt}-\mathrm{yr}$.

The overall clinical performance of the CarboMedics valve prosthesis is in our experience satisfactory at this length of follow-up and comparable to that of other current bileaflet devices. Thrombotic phenomena were in the current study still a point of concern, and hemorrhagic complications, although low, did not completely disappear. Improvement in anticoagulation strategies and control systems is essential, even with newer mechanical heart valve prostheses, if we want to get better results in terms of the thrombosis-hemorrhage balance.

\section{REFERENCES}

1. Schoen FJ. Valvular heart disease: cardiac valve replacement. In: Schoen FJ, ed. Interventional and surgical cardiovascular pathology: clinical correlations and basic principles. Philadelphia: WB Saunders, 1989:109-71.

2. Duncan JM, Cooley DA, Reul GJ, et al. Durability and low thrombogenicity of the St. Jude Medical valve at 5-year follow-up. Ann Thorac Surg 1986;42:500-5.

3. Kratz JM, Crawford FA, Sade RM, Crumbley AJ, Stroud MR. St. Jude prosthesis for aortic and mitral valve replacement: a ten year experience. Ann Thorac Surg 1993;56:462-8.

4. Khan S, Chaux A, Matloff J, et al. The St. Jude Medical valve: experience with 1000 cases. J Thorac Cardiovasc Surg 1994; 108:1010-20.

5. Aoyagi S, Oryoji A, Nishi Y, Tanaka K, Kosuga K, Oishi K. Long-term results of valve replacement with the St. Jude Medical valve. J Thorac Cardiovasc Surg 1994;108:1021-9.

6. Edmunds LH, Clark RE, Cohn LH, Miller DC, Wesel RD. Guidelines for reporting morbidity and mortality after cardiac valvular operations. J Thorac Cardiovasc Surg 1988;96: 351-3.

7. Kaplan EL, Meier P. Nonparametric estimation from incomplete observations. J Am Stat Assoc 1958;53:457-81.

8. Gott VL, Daggett RL, Koepke DE, Rowe GG, Young WP. A hinged-leaflet valve for total replacement of the human aortic valve. J Thorac Cardiovasc Surg 1964;48:713.

9. Kalke BR, Lillehei CW, Kaster RL. Evaluation of a doubleleaflet prosthetic heart valve of new design for clinical use. In: Brewer LA, ed. Prosthetic heart valves. Springfield, Illinois: Charles Thomas, 1969:285-302.

10. Emery RW, Mettler E, Nicoloff DM. A new cardiac prosthesis: the St. Jude Medical cardiac valve-in vivo results. Circulation 1979;60(Suppl):II148-54.

11. Emery RW, Palmquist WE, Mettler E, Nicoloff DM. A new cardiac valve prosthesis: in vitro results. Trans Am Soc Artif Intern Organs 1978;24:550-6.

12. Emery RW, Nicoloff DM. The St. Jude Medical cardiac valve prosthesis: in vitro studies. J Thorac Cardiovasc Surg 1979; 78:269-76. 
13. Chaux A, Czer LSC, Matloff JM, et al. The St. Jude Medical bileaflet valve prosthesis: a 5 year experience. J Thorac Cardiovasc Surg 1984;88:706-17.

14. Montalescot G, Thomas D, Drobinsky G, et al. Clinical and ultrasound results after aortic valve replacement: intermediate-term follow-up with the St. Jude Medical prosthesis. Am Heart J 1989;118:104-13.

15. Johnston RT, Weerasena NA, Butterfield M, Fisher J, Spyt TJ. CarboMedics and St. Jude Medical bileaflet valves: an in vitro and in vivo comparison. Eur J Cardiothorac Surg 1992;6:267-71.

16. Okita Y, Miki S, Kusuhara K, et al. Analysis of left ventricular motion after mitral valve replacement with a technique of preservation of all chordae tendineae: comparison with conventional mitral valve replacement or mitral valve repair. J Thorac Cardiovasc Surg 1992;104:786-95.

17. Ihlen H, Mostad P, Simonsen S, et al. Hemodynamic evaluation of the CarboMedics prosthetic heart valve in the aortic position: comparison of noninvasive and invasive techniques. Am Heart J 1992;123:151-9.

18. Chambers J, Cross M, Deverall PB, Sowton E. Echocardiographic description of the CarboMedics bileaflet prosthetic heart valve. J Am Coll Cardiol 1993;21:398-405.

19. Mitchell RS, Miller DC, Stinson EB, et al. Significant patientrelated determinants of prosthetic valve performance. $J$ Thorac Cardiovasc Surg 1986;91:807-17.

20. Rahimtoola SH. Valvular heart disease: a perspective. J Am Coll Cardiol 1983;1:199-215.
21. Hirsh J, Dalen JE, Deykin D, Poller L. Oral anticoagulants: mechanism of action, clinical effectiveness and optimal theraupeutic range. Chest 1992;102(Suppl):445S-55S.

22. Castillón L, Pareja JG, Ruiz MC, Jiménez MAG, Infantes C, Pérez-Duarte E. Five years experience with the BjörkShiley Monostrut valve in 2726 patients: a Spanish multicentre study. In: Bodnar E, ed. Surgery for heart valve disease. London: Proceedings of the 1989 Symposium, 1989:268-85.

23. Copeland JG. An international experience with the CarboMedics prosthetic heart valve. J Heart Valve Dis 1995;4:5662.

24. Orszulak TA, Schaff HV, DeSmet JM, Danielson GK, Pluth JR, Puga FJ. Late results of valve replacement with the Björk-Shiley valve (1973 to 1982). J Thorac Cardiovasc Surg 1993; 105:302-12.

25. Altman R, Rouvier J, Gurfinkel E, et al. Comparison of two levels of anticoagulant therapy in patients with substitute heart valves. J Thorac Cardiovasc Surg 1991;101:427-31.

26. Saour JN, Steck JO, Mamo LAR, Gallus AS. Trial of different intensities of anticoagulation in patients with prosthetic heart valves. N Engl J Med 1990;322:428-32,

27. Cannegieter SC, Rosendaal FR, Wintzen AR, van der Meer FJM, Vandenbroucke JP, Briët E. Optimal anticoagulant therapy in patients with mechanical heart valves. $\mathrm{N}$ Engl $\mathrm{J}$ Med 1995;333:11-7.

28. Fihn SD. Aiming for safe anticoagulation. N Engl J Med 1995;333:54-5. 